IRSH 65 (2020), pp. 23 I doi:I0.1017/So020859020000279

(C) 2020 Internationaal Instituut voor Sociale Geschiedenis

\title{
Women and Gender in the Mines: Challenging Masculinity Through History: An Introduction
}

\section{ERRATUM}

Rossana BarRagán Romano And Leda Papastefanaki

doi: $10.1017 /$ S002085901 9000774 , published online by Cambridge University Press, I 2 February 2020.

The publishers apologise that due to a page setting error the last sentence of the first footnote detailing the paper's acknowledgments, "Many thanks also to Marie-José Spreeuwenberg for her invaluable engagement." was incorrectly moved to the last line of the abstract.

The publishers also apologise that in the Bibliography accompanying this article, the p. 228 reference:

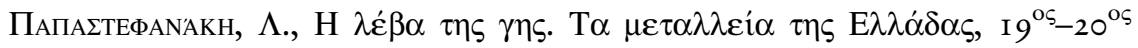
$\alpha \iota \omega ́ v \alpha \varsigma$ (Athens, 20I7).

is incorrect.

This should read:

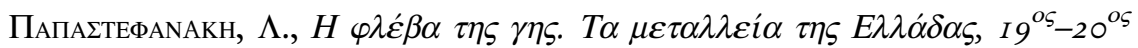
$\alpha \iota \omega ́ v \alpha \varsigma$ (Athens, 20I7).

\section{REFERENCE}

Rossana Barragán Romano and Leda Papastefanaki, "Women and Gender in the Mines: Challenging Masculinity Through History: An Introduction", International Review of Social History, 65:I (2020), pp. I-40. 